\title{
Hemodynamic Failure in a Hanging Man: Think About the Tension Pneumothorax!
}

\author{
Oscar Thabouillot; ${ }^{1,2}$ Clément Derkenne; ${ }^{1,2}$ Kilian Bertho; ${ }^{1,2}$ Matthias Huck; ${ }^{2,3}$ Bertrand Prunet ${ }^{1,2}$
}

1. Service Médical d'Urgence, Brigade de Sapeurs-Pompiers de Paris, Paris, France

2. Service de Santé; des Armées, France

3. Service d'Anesthésie, Hôpital d'Instruction des Armées de Bégin, Saint-Mandé, France

Correspondence:

Oscar Thabouillot

Service Médical d'Urgence

Brigade de Sapeurs-Pompiers de Paris

1 place Jules Renard

75017 Paris, France

E-mail: thabouillot@hotmail.com

Conflicts of interest: none

Keywords: cardiorespiratory arrest; pneumomediastinum; pneumothorax

Abbreviations:

ALS: Advanced Life Support

BLS: Basic Life Support

CRA: cardiorespiratory arrest

RSCA: return of spontaneous cardiac activity

Received: November 22, 2018

Accepted: January 20, 2019

doi:10.1017/S1049023X19004369
Thabouillot O, Derkenne C, Bertho K, Huck M, Prunet B. Hemodynamic failure in a hanging man: think about the tension pneumothorax! Prehosp Disaster Med. 2019;34(3):343-344.

\section{Report}

We report the case of a 33-year-old man who was treated after cardiorespiratory arrest (CRA) following hanging. His medical record contained three attempted suicides by voluntary drug poisoning. An Advanced Life Support (ALS) team and a Basic Life Support (BLS) team were dispatched altogether for a complete hanging without dropping. The patient was still hanged when the BLS team arrived, and the estimated hanging time was less than five minutes. The knot was in a right anterolateral position, and the height between the floor and the feet was approximately 50 centimeters. The ALS team arrived while chest compressions had just begun, with no visible life signs and bilateral nonreactive mydriasis. The electric rhythm showed an ASYSTOLE. After an orotracheal intubation (using the four-handed technique to preserve the cervical spine/with the cervical collar) and following a $1 \mathrm{mg}$ adrenalin injection, a return of spontaneous cardiac activity (RSCA) was observed. The total low flow duration was four minutes. The initial constants after the RSCA were: noninvasive blood pressure $147 / 88 \mathrm{mmHg}$, heart rate $130 \mathrm{bpm}$, and $\mathrm{SpO}_{2}$ was $99 \%$ with a $100 \% \mathrm{FiO}_{2}$. Expired $\mathrm{CO}_{2}$ was $37 \mathrm{mmHg}$. The electrocardiogram showed sinus tachycardia with no conduction or repolarization disorder. Post-intubation lung auscultation evidenced a symmetric vesicular murmur in both lung fields. In the minutes following the RSCA, blood pressure dropped rapidly and required a blood volume increase (in total, $700 \mathrm{~mL}$ of isotonic saline) and the administration of vasopressors (norepinephrine) with a maximum at $3 \mathrm{mg}$ per hour. Despite these actions, 10 minutes after the RSCA, the patient collapsed and blood pressure was $70 / 37 \mathrm{mmHg}$. The radial pulse was becoming thready and hardly noticeable. A clinical exam of the patient showed, on the left side, an absence of rising of the hemithorax and a silence on auscultation. A left compressive pneumothorax was suspected. The inspection and auscultation of the right lung were normal. An exsufflation on the midclavicular line, at the second intercostal space, using a $35 \mathrm{~mm}$ long $14 \mathrm{~g}$ catheter, was ineffective. The patient was moderately overweight (approximately $100 \mathrm{~kg}$ and $170 \mathrm{~cm}$ tall; body mass index $=34.6$ ). The overweight condition was probably responsible for the ineffectiveness of the exsufflation with the needle. A thoracostomy was performed at the fourth intercostal space level, on the axillary line. Following this gesture, which objectified the presence of air in the pleural cavity, hemodynamics stabilized and the patient was weaned off norepinephrine within minutes. The patient was transported with stable hemodynamic functions without amines, and also showed signs of awakening.

On arrival at the hospital, a cranio-thoracic computed tomography scan confirmed the presence of a pneumothorax and a pneumomediastinum (Figure 1 and Figure 2). There was no cervical lesion. The patient died from multiple organ dysfunction syndrome 48-hours after being admitted in the intensive care unit.

\section{Discussion}

There are two types of hanging: hanging causing suffocation by compression of the soft structures of the neck, visible in suicides; and the so-called "judicial" hanging, where the death is caused by a fracture of the dens of the odontoid and which requires a rope long enough and a sufficiently high fall. This hanging is called "judicial" because it is used for executions. In the context of suicides, the majority of hangings lead to suffocation. Reaching a location high enough to make a "judicial" hanging is difficult. In our case, it was a hanging by suffocation. In such cases, there are two sub-types: "complete" hangings, where the patient does not have feet touching the floor; and "incomplete" hangings, where 


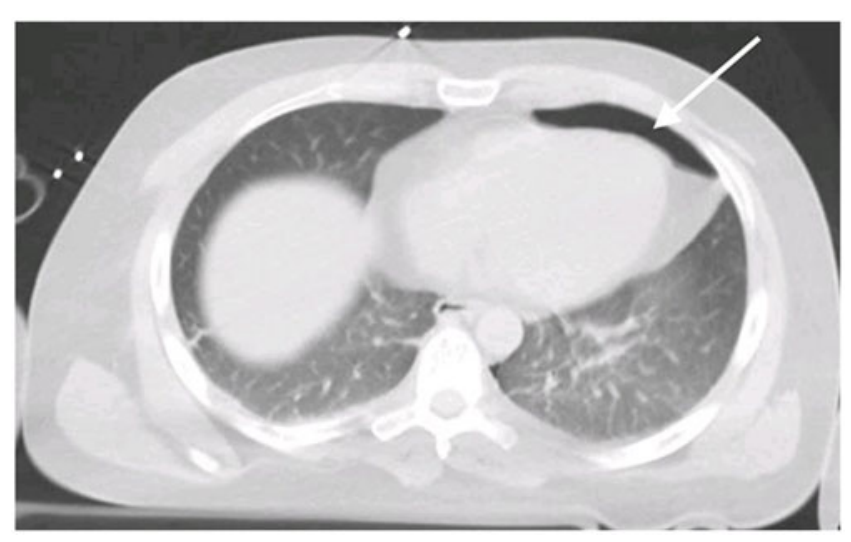

Thabouillot $\odot 2019$ Prehospital and Disaster Medicine

Figure 1. Pneumothorax.

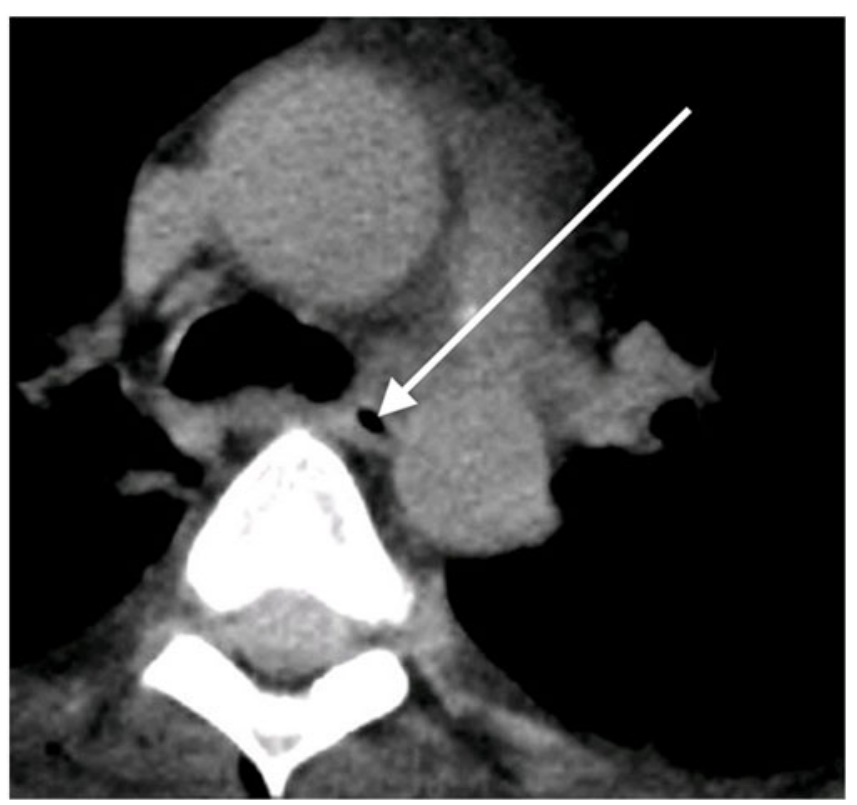

Thabouillot @ 2019 Prehospital and Disaster Medicine

Figure 2. Pneumomediastinum. the patient still has partial support with the floor. The most commonly observed lesions are soft tissue compressions, ${ }^{1}$ anoxiarelated cerebral edema, and venous return blockage by the jugular veins; much less frequently observed are cervical spine lesions. ${ }^{2}$ The prognosis of a hanging man in CRA is very poor, ${ }^{3}$ and the delay before unhanging is probably a major prognostic factor.

Thus, the resuscitation of a hanging man must take into account all these different elements. Re-oxygenation must be a priority because it is a hypoxic CRA, unlike cardiogenic CRA, for which massage and defibrillation are the major issue. Intubation should be done quickly. The more time that passes, the greater the risk that edema of the upper airways develops, which makes intubation and ventilation difficult. The low prevalence of spinal lesions justifies the temporary removal of immobilization mechanisms of the cervical spine, under protection of the implementation of a manual holding (four-handed intubation technique).

In rare cases, large pressure amplitudes caused by major inspiratory/expiratory efforts with blockage of the upper airways may cause barotraumatic lesions such as pneumothorax or pneumomediastinum. ${ }^{4,5}$ Mechanical ventilation of hanging patients may aggravate these lesions and make the pneumothorax compressive.

In many other situations in emergency medicine, the tension pneumothorax must be quickly evoked by the practitioner, despite coarse and very non-specific signs. This involves, for example, traumatic cardiac arrest, respiratory, and hemodynamic deterioration of the patient who has just been ventilated with positive pressure (chronic obstructive pulmonary disease and emphysematous, in particular). In the case of a hanging man, because of the low prevalence of this type of lesion, it is nevertheless worthwhile to know this mechanism well. The knowledge of these lesions is important because it allows early and rapid management of lesions that can lead to CRA, easily accessible to effective treatment (ie, exsufflation), from the prehospital care.

\section{References}

1. Zátopková L, Janík M, Urbanová P, Mottlová J, Hejna P. Laryngohyoid fractures in suicidal hanging: a prospective autopsy study with an updated review and critical appraisal. Forensic Sci Int. 2018;290:70-84.

2. Salim A, Martin M, Sangthong B, Brown C, Rhee P, Demetriades D. Nearhanging injuries: a 10-year experience. Injury. 2006;37(5):435-439.

3. Escutnaire J, Ducrocq F, Singier A, et al. Can we define termination of resuscitation criteria in out-of-hospital hanging? Prehosp Emerg Care. 2018. E-pub ahead of print.

4. Dhillon NK, Tatum JM, Ley EJ, Barmparas G. Tension pneumoperitoneum after hanging. Am Surg. 2018;84(3):e108-e109.

5. Picetti E, Rossi I, Antonini V, Volpi A. Pneumomediastinum and emphysema of the neck after a suicide attempt by hanging. Minerva Anestesiol. 2012;78(1):111. 